\title{
Serum YKL-40 Levels and Chitotriosidase Activity in Patients with Beta-Thalassemia Major
}

\author{
Maria Musumeci, ${ }^{1}$ Vincenzo Caruso, ${ }^{2}$ Emilia Medulla, ${ }^{2}$ Venerando Torrisi, ${ }^{3}$ \\ Roberta Migale, ${ }^{4}$ Silvia Angeletti, ${ }^{1}$ and Salvatore Musumeci ${ }^{5}$ \\ ${ }^{1}$ Center for Integrated Research, Department of Laboratory Medicine and Microbiology, Campus Bio-Medico University of Rome, \\ 00128 Rome, Italy \\ ${ }^{2}$ Center of Microcitemia, 95123 Catania, Italy \\ ${ }^{3}$ IRMA, Acireale, 95024 Catania, Italy \\ ${ }^{4}$ Department of Surgery and Cancer, Parturition Research Group, Institute of Reproduction and Developmental Biology, \\ Imperial College London, London W12 0NN, UK \\ ${ }^{5}$ Department of Chemical Sciences, University of Catania and Institute of Biomolecular Chemistry, CNR, \\ 95125 Catania, Italy
}

Correspondence should be addressed to Salvatore Musumeci; smusumeci@tiscalinet.it

Received 31 October 2013; Accepted 29 January 2014; Published 8 April 2014

Academic Editor: Yi-Chia Huang

Copyright (C) 2014 Maria Musumeci et al. This is an open access article distributed under the Creative Commons Attribution License, which permits unrestricted use, distribution, and reproduction in any medium, provided the original work is properly cited.

Background. YKL-40 association with human disease has been the object of many years of investigation. $\beta$-thalassemia patients are affected by hepatic siderosis, which determines a fibrotic process and tissue remodelling. Chitotriosidase has been found to be increased in thalassemic patients returning to normal in patients submitted to bone marrow transplantation. YKL-40 is associated with macrophage activation in liver and in other tissues. The aim of the study was to analyse the level of serum YKL- 40 and plasma chitotriosidase activity of patients with beta-thalassemia to assess whether their expression correlates with liver disease and degree of liver siderosis. Methods. Expression of YKL-40 and chitotriosidase as a marker of inflammation in 69 thalassemic patients were evaluated. We sought to investigate whether these two chitinases could be considered as a significant biomarker to evaluate therapy effectiveness. Results. Surprisingly we found normal value of YKL-40. We, also, analysed chitotriosidase activity in the same patients that was slightly increased as a consequence of macrophage activation. Conclusions. These data would suggest a good treatment for these patients.

\section{Introduction}

The glycosyl hydrolase family 18 of chitinases is an ancient gene family widely expressed from prokaryotes to eukaryotes. In mammals, despite the absence of endogenous chitin, a number of chitinases and chitinase-like proteins have been identified and their role is yet to be fully elucidated. YKL40 is a highly conserved glycoprotein belonging to the family of glycosyl hydrolase 18. The YKL-40 (also termed chitinase 3-like 1) inhibits oxidant-induced lung injury, augments adaptive Th 2 immunity, regulates apoptosis, stimulates alternative macrophage activation, and contributes to fibrosis and wound healing [1].
The YKL gene is localized on chromosome 1q32.1 and two different splice forms are reported: isoform 1 containing exon 1-10 and isoform 2 in which exon 8 has been spliced out [2]. YKL-40 is expressed by macrophage cells during late stage of differentiation [3], by tumor-associated macrophages [4], by infiltrating macrophages in various inflammatory conditions such as rheumatoid arthritis and osteoarthritis [5], and by macrophage and giant cells in arteritis vessel [6]. YKL-40 is also overexpressed in macrophages of early atherosclerotic lesions [7] and in macrophage of bronchial tissue [8].

Increased YKL- 40 protein expression is noted in patients with alcoholic liver disease and concurrent chronic hepatitis C virus infection $[9,10]$. YKL-40 is not expressed in normal 
liver tissue except in mesenchymal structure of portal tract [11]. Interestingly, in chronic viral hepatitis portal tracts are the primary sites of fibrotic tissue formation from which fibrotic liver disease will drive the changes in liver architecture associated with the infection.

Although a wide body of evidences associates YKL-40 expression with several pathologies, its biological role is still poorly understood.

In vitro studies suggested a role for YKL-40 as a proliferation factor in synovial cells and chondrocytes and a suppressive effect on cytokine signalling in connective tissue cells $[12,13]$.

Chitotriosidase (Chit) is a chitinolytic enzyme selectively produced by activated macrophages. Serum chit activity is significantly higher in individuals suffering from atherosclerotic diseases, Gaucher disease (beta-glucocerebrosidase deficiency) [14], sarcoidosis [15], malaria [16], and thalassemia [17].

Beta-thalassemia is a haematological disorder caused by a genetic defect in the synthesis of beta globin chains, resulting in severe haemolytic anaemia, inefficient erythropoiesis, and enormous expansion of reticuloendothelial system [18]. Lifelong transfusion regimens are essential to alleviate anaemia. Although regular blood transfusions have largely improved the prognosis, iron overload, especially in the liver (liver siderosis), and high risk of hepatitis $\mathrm{C}$ infections constitute a real threat to the quality of life of beta-thalassemia patients [19]. In beta-thalassemia patients both iron overload and HCV-related liver disease lead, albeit through different mechanisms, to hepatocellular necrosis, fibrosis, and cirrhosis. An iron chelation treatment is necessary to counteract the damaging effects of siderosis. Controlled regimens of blood transfusions together with interferon treatment of chronic hepatitis $C$ have significantly improved the life of patients in duration and quality [20].

Plasma chitotriosidase activity was found to be increased to a variable extent in Sicilian patients diagnosed with beta-thalassemia major $[17,21]$. All patients showed peripheral anaemia and considerable enlargement of the reticuloendothelial system. Since YKL-40 is associated with macrophage activation in liver and in other tissues, the aim of this study was to analyse the levels of YKL-40 and chitotriosidase activity in plasma of patients with betathalassemia to assess whether their expression correlates with liver disease and degree of liver siderosis. Additionally we sought to investigate whether these two chitinases could be considered as a significant biomarker to evaluate therapy effectiveness.

\section{Material and Methods}

2.1. Patients. 69 Sicilian patients with beta-thalassemia, 34 males and 35 females, were enrolled in this study (median age 33, range 15-69). The blood transfusion regimen started since the 24 months of age, associated to iron chelating therapy (40 mg/kg/day) according to ad hoc Italian protocol. Liver biopsy was performed in 20 patients, when serum transaminases resulted constantly elevated with viral hepatitis markers. A group of 21 healthy subjects (median age
38 , range $27-47$ years) were enrolled as controls. They were characterized by not being on medication and having no sign of preexisting disorders such as joint, liver, metabolic or endocrine diseases, or malignancy.

2.2. Clinical and Serological Parameters. Blood samples were collected before the last transfusion of concentrated red cells, between 8 and 12 a.m. Serum and plasma samples were analyzed either immediately or snap-frozen and stored at $-80^{\circ} \mathrm{C}$. Transaminases (ALT, AST), gamma-GT (GGT), LDH, total proteins, albumin/globulin ratio, and ferritin levels were determined by routine methods. The sideruria was monitored in these patients after Desferal load $(500 \mathrm{mg} /$ day). Level of liver siderosis was measured with SQUID magnetometer and magnetic resonance technology.

2.3. Chitotriosidase Activity. The chitotriosidase assay was based on the method described by Hollak et al. [14]. Chitotriosidase activity was measured by incubating $5 \mu \mathrm{L}$ plasma with $100 \mu \mathrm{L}$ of $22 \mu \mathrm{mol} / \mathrm{L} 4$-methylumbelliferyl-bd-N,N8,N9 triacetylchitotriose (Sigma Chemical CO) in

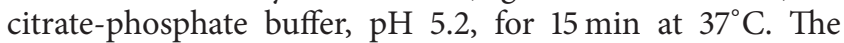
reaction was stopped by the addition of $2 \mathrm{~mL}$ of $0.5 \mathrm{~mol} / \mathrm{L}$ $\mathrm{Na}_{2} \mathrm{CO}_{3}-\mathrm{NaHCO}_{3}$ buffer, $\mathrm{pH}$ 10.7, and the fluorescence was read on a Perkin Elmer fluorimeter with excitation of $365 \mathrm{~nm}$ and emission of $450 \mathrm{~nm}$. Chitotriosidase activity was measured as nanomoles of substrate hydrolysed per minute per $\mathrm{mL}(\mathrm{nmol} / \mathrm{mL} / \mathrm{hr})$. Plasma chitotriosidase activity was measured in duplicate and coefficient of variation was less than $5 \%$ in all measurements.

2.4. YKL-40 Determination. Serum YKL-40 concentrations were determined by a commercial enzyme-linked immunosorbent assay (Quidel, Santa Clara, CA, USA). The intraassay and interassay variations were $3.6 \%$ and $5.3 \%$, respectively. The sensitivity of the assay was $20 \mathrm{ng} / \mathrm{mL}$. The samples were measured in duplicate.

2.5. Statistical Analysis. The statistical analysis was carried out with Origin Software. The results are expressed as median and range. Correlations between the different parameters were calculated by Spearman $P$ test. $P$ values $<0.05$ were considered significant.

\section{Results}

Table 1 shows the median level of serum YKL-40 and plasma chitotriosidase in thalassemic patients and in healthy controls. Two patients showed low values of chitotriosidase (1.03 and 2.4), which may result from genetic polymorphisms of CHIT gene affecting its expression levels. Median levels of transaminases AST and ALT, GGT, albumin/globulin ratio, $\mathrm{LDH}$, total proteins, ferritin, SQUID, and MR are also shown in Table 1. One patient was HBsAg positive and 51 were anti-HBs positive following $\mathrm{HBV}$ vaccination. 48 patients were anti-HCV positive; however, only in 16 patients $\mathrm{HCV}$ RNA was detected. Two patients of this group underwent interferon/ribavirin treatment for permanent high transaminase levels. Two patients were HIV positive in treatment 
TABLE 1: Clinical and serological parameter in 69 thalassemic patients and healthy controls.

\begin{tabular}{|c|c|c|c|c|}
\hline Parameters & Thalassemic patients & Reference values & Healthy controls & Spearman $P$ test \\
\hline Age (years) & $\begin{array}{c}33 \\
(15-69)\end{array}$ & - & $\begin{array}{c}38 \\
(27-47)\end{array}$ & $P=0.60$ \\
\hline Sex $M / F$ & $34 / 35$ & - & $10 / 11$ & - \\
\hline AST U/L & $\begin{array}{c}23 \\
(9-156)\end{array}$ & Up to 37 & $\begin{array}{c}17 \\
(8-34)\end{array}$ & $P=0.63$ \\
\hline ALT U/L & $\begin{array}{c}26 \\
(8-142)\end{array}$ & Up to 78 & $\begin{array}{c}27 \\
(17-54)\end{array}$ & $P=0.54$ \\
\hline GGT U/L & $\begin{array}{c}21 \\
(5-153)\end{array}$ & $15-85$ & $\begin{array}{c}20 \\
(9-82)\end{array}$ & $P=0.46$ \\
\hline $\mathrm{LDH} \mathrm{U/L}$ & $\begin{array}{c}325 \\
(166-1082)\end{array}$ & $0-248$ & $\begin{array}{c}170.5 \\
(123-208)\end{array}$ & $P=0.84$ \\
\hline Total proteins gr/dL & $\begin{array}{c}7.2 \\
(6.5-7.25)\end{array}$ & $6.4-8.3$ & $\begin{array}{c}7.25 \\
(6.5-8.25)\end{array}$ & $P=0.07$ \\
\hline Albumin/globulin ratio & $\begin{array}{c}1.56 \\
(0.93-1.28)\end{array}$ & $1.10-2.40$ & $\begin{array}{c}1.55 \\
(1.22-1.87)\end{array}$ & $P=0.95$ \\
\hline Ferritin ng/mL & $\begin{array}{c}1250 \\
(89-9110)\end{array}$ & $\begin{array}{c}\text { F 8-252 } \\
\text { M 26-388 }\end{array}$ & $\begin{array}{c}157 \\
(34-314)\end{array}$ & $P=0.52$ \\
\hline SQUID & $\begin{array}{c}1296 \\
(254-3379)\end{array}$ & - & - & - \\
\hline MR & $\begin{array}{c}5.61 \\
(0.38-43)\end{array}$ & - & - & - \\
\hline Chitotriosidase $\mathrm{nmol} / \mathrm{mL} / \mathrm{hr}$ & $\begin{array}{c}84.38 \\
(1.03-519)\end{array}$ & - & $\begin{array}{c}44 \\
(0.6-73)\end{array}$ & $P=0.005$ \\
\hline YKL-40 $\mu \mathrm{g} / \mathrm{L}$ & $\begin{array}{c}37.6 \\
(14-117.32) \\
\end{array}$ & - & $\begin{array}{c}29.18 \\
(17.5-111.4) \\
\end{array}$ & $P=0.27$ \\
\hline
\end{tabular}

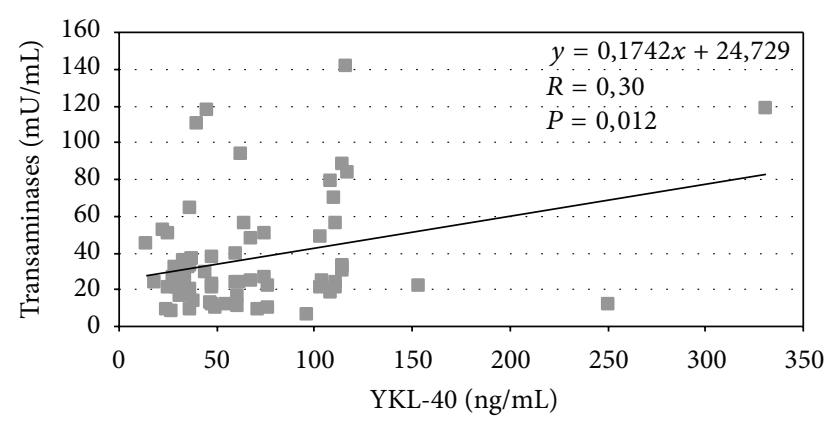

FIGURE 1: Correlation between serum transaminases and serum YKL-40 in 69 thalassemic patients.

with antiretroviral therapy. Only one patient was affected by intermediate thalassaemia. 38 patients were splenectomized.

YKL-40 levels correlate with liver transaminases $(P=$ 0.012 ) (Figure 1) and a similar correlation was observed between chitotriosidase and transaminases $(P=0.034)$ (Figure 2). The correlation between chitotriosidase and YKL40 was significant $(P=0.0001)$ (Figure 3$)$, supporting the hypothesis that the mechanisms regulating the expression of these two chitinases are interdependent. The correlation between SQUID and ferritin was significant $(P=0.019)$

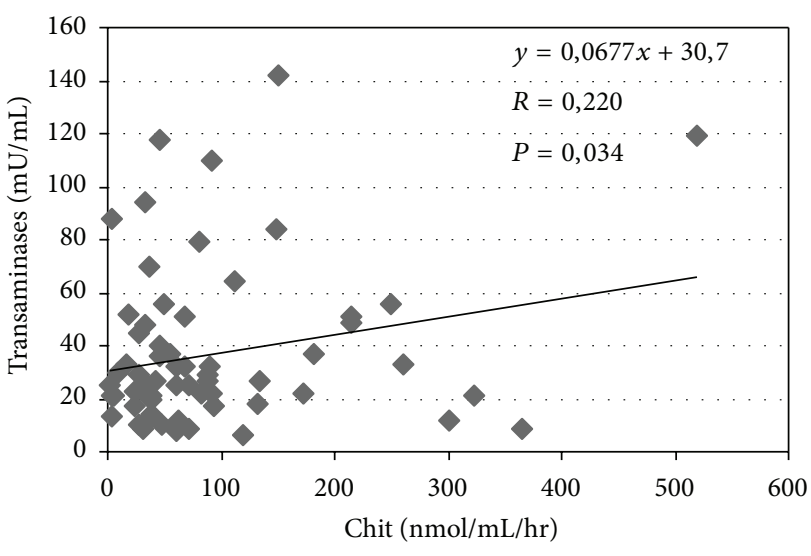

FIGURE 2: Correlation between serum transaminases and plasma chitotriosidase (Chit) in 69 thalassemic patients.

(Figure 4). Correlation between YKL-40 and ferritin $(P=$ $0.0008)$ and the correlation between chitotriosidase and ferritin were also significant $(P=0.00001)$. The liver biopsy showed different results with a prevalence of liver fibrosis and different degree of fibrosis (fibrosis $1^{\circ} 4$, fibrosis $2^{\circ} 3$, and mild fibrosis 2). Four patients showed chronic active hepatitis $\mathrm{HCV}+$ with siderosis, while three showed siderosis and three 


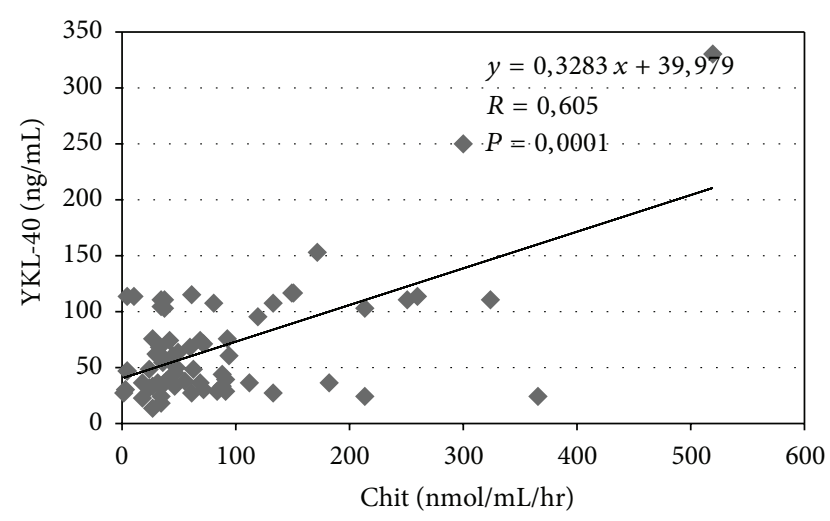

FIGURE 3: Correlation between serum YKL-40 and plasma chitotriosidase (Chit) in 69 thalassemic patients.

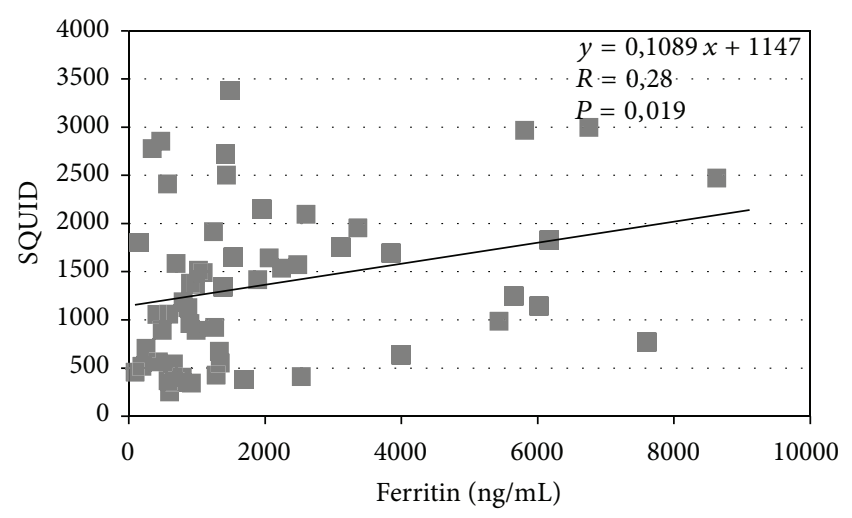

FIGURE 4: Correlation between SQUID and Ferritin in 69 thalassemic patients.

chronic active hepatitis with fibrosis, five chronic low activity hepatitis (Lic 12, Lic 6.9, Lic 14.8, Lic 14, and Lic 15). Liver biopsy showed enlarged portobiliary space with fibrosis and lymphocytic infiltration, sclerosiderotic nodules, and signs of slight chronic hepatitis. No statistically significant correlation was found between histological alteration and level of YKL40 and chitotriosidase.

\section{Discussion}

Due to a significant association of elevated concentration of plasma YKL-40 with various diseases, considerable effort has been devoted to the elucidation of its biological activity.

Increased serum concentrations of YKL-40 were observed in patients affected by pathologies involving extracellular matrix degradation and angiogenesis, such as rheumatoid arthritis [22], hepatic fibrosis [23], and osteoarthritis [24], as well as cancer [1].

Increased concentrations of YKL-40 were detected not only in tissue-localised inflammation, but also systemically in serum of patients with rheumatoid arthritis [25]. YKL40 mRNA expression was higher in macrophages in early atherosclerotic lesions and in infiltrating macrophages [26]. YKL-40 can act as an adhesion and migration factor in vascular cells and it may have a role in molecular processes involved in vascular occlusion and heart development [27].

Increased production of YKL-40 is an indicator of liver pathology. YKL-40 is differentially upregulated in cirrhotic liver on the end-stage of hepatitis C virus- (HCV-) induced liver cirrhosis [28]. Serum level of YKL-40 correlates with its mRNA expression in liver [29] and was suggested to be a useful noninvasive marker for evaluation of the degree of fibrosis as well as therapy effectiveness in patients with HCVassociated liver disorders [30]. Increased plasma levels of YKL-40 were also suggested to reflect the progression of liver fibrosis in alcoholics [31].

Beta-thalassemia patients are affected by liver siderosis which determines a fibrotic process and an extracellular tissue remodelling. Given the strong association of YKL40 with inflammation, higher levels of this molecule were expected.

However, in this study the level of YKL-40 was found to be lying in the normal range and only a slight correlation was found with the liver status as demonstrated by liver transaminases. Also the presence of anti-HCV antibodies in these patients, which is often associated with chronic hepatitis, does not correlate with YKL-40 levels. In other studies the elevated serum YKL-40 is associated with poor prognosis and survival in patients with alcoholic liver disease [32] and in patients with coronary artery disease [33]. A possible explanation of our results is maybe the timely and correct treatment of the thalassemia patients enrolled in this study. Indeed the chronic hepatitis was controlled by interferon/ribavirin therapy and no relapse was reported. Also, the compliance to iron chelating treatment was effective to reduce the liver siderosis. Moreover, a correct blood transfusion regimen is effective in reducing intestinal iron absorption and the hyperhemolysis, which are the main causative factors of liver siderosis.

We think that YKL-40 may be considered as a marker of correct treatment and its dosage could represent a new marker for prognosis. This last hypothesis could be supported by the observation that the elevated level of another chitinase, chitotriosidase, produced by activated macrophage, returns to normal values in patients following bone marrow transplant, which at the moment is considered as the best therapeutic option available [34]. Nevertheless, the levels of chitotriosidase in thalassemic patients are just slightly elevated compared to healthy individuals. These data suggest that in patients with thalassemia the improved treatment with regular transfusion regimen and the associated iron chelation therapy could result in an apparent clinical and laboratory recovery.

\section{Conclusions}

Our results could support the idea that current regimens of transfusions and the associated chelation therapy have definitely contributed to ameliorate the health status of thalassemia patients. This hypothesis could be, probably, explained by testing the chitinases levels in less developed countries where transfusion regimens and chelation therapy are not readily available. 


\section{Conflict of Interests}

The authors declare no conflict of interests in the research.

\section{Acknowledgment}

The authors thank the precious help of Mr. Rapicavoli Giuseppe for the measurement of chitotriosidase.

\section{References}

[1] J. S. Johansen, "Studies on serum YKL-40 as a biomarker in diseases with inflammation, tissue remodelling, fibroses and cancer," Danish Medical Bulletin, vol. 53, no. 2, pp. 172-209, 2006.

[2] M. Rehli, S. W. Krause, and R. Andreesen, "Molecular characterization of the gene for human cartilage gp-39 (CHI3L1), a member of the chitinase protein family and marker for late stages of macrophage differentiation," Genomics, vol. 43, no. 2, pp. 221-225, 1997.

[3] M. Rehli, H.-H. Niller, C. Ammon et al., "Transcriptional regulation of CHI3L1, a marker gene for late stages of macrophage differentiation," Journal of Biological Chemistry, vol. 278, no. 45, pp. 44058-44067, 2003.

[4] N. Junker, J. S. Johansen, C. B. Andersen, and P. E. G. Kristjansen, "Expression of YKL-40 by peritumoral macrophages in human small cell lung cancer," Lung Cancer, vol. 48, no. 2, pp. 223-231, 2005.

[5] B. Volck, J. S. Johansen, M. Stoltenberg et al., "Studies on YKL40 in knee joints of patients with rheumatoid arthritis and osteoarthritis. Involvement of YKL-40 in the joint pathology," Osteoarthritis and Cartilage, vol. 9, no. 3, pp. 203-214, 2001.

[6] J. S. Johansen, B. Baslund, C. Garbarsch et al., "YKL-40 in giant cells and macrophages from patients with giant cell arteritis," Arthritis \& Rheumatology, vol. 42, pp. 2624-2630, 1999.

[7] R. G. Boot, T. A. E. Van Achterberg, B. E. Van Aken et al., "Strong induction of members of the chitinase family of proteins in atherosclerosis: chitotriosidase and human cartilage gp39 expressed in lesion macrophages," Arteriosclerosis, Thrombosis, and Vascular Biology, vol. 19, no. 3, pp. 687-694, 1999.

[8] G. L. Chupp, C. G. Lee, N. Jarjour et al., "A chitinase-like protein in the lung and circulation of patients with severe asthma," The New England Journal of Medicine, vol. 357, no. 20, pp. 2016-2027, 2007.

[9] J. S. Johanshn, S. Møller, P. A. Price et al., "Plasma YKL-40: a new potential marker of fibrosis in patients with alcoholic cirrhosis?" Scandinavian Journal of Gastroenterology, vol. 32, no. 6, pp. 582-590, 1997.

[10] S. M. Kamal, B. Turner, Q. He et al., "Progression of fibrosis in hepatitis $\mathrm{C}$ with and without schistosomiasis: correlation with serum markers of fibrosis," Hepatology, vol. 43, no. 4, pp. 771779, 2006.

[11] M. Pinzani, "Liver fibrosis," Springer Seminars in Immunopathology, vol. 21, no. 4, pp. 475-490, 1999.

[12] F. de Ceuninck, S. Gaufillier, A. Bonnaud, M. Sabatini, C. Lesur, and P. Pastoureau, "YKL-40 (cartilage gp-39) induces proliferative events in cultured chondrocytes and synoviocytes and increases glycosaminoglycan synthesis in chondrocytes," Biochemical and Biophysical Research Communications, vol. 285, no. 4, pp. 926-931, 2001.
[13] H. Ling and A. D. Recklies, "The chitinase 3-like protein human cartilage glycoprotein 39 inhibits cellular responses to the inflammatory cytokines interleukin- 1 and tumour necrosis factor- $\alpha$," Biochemical Journal, vol. 380, no. 3, pp. 651-659, 2004.

[14] C. E. M. Hollak, S. van Weely, M. H. J. van Oers, and J. M. F. G. Aerts, "Marked elevation of plasma chitotriosidase activity. A novel hallmark of Gaucher disease," Journal of Clinical Investigation, vol. 93, no. 3, pp. 1288-1292, 1994.

[15] Y. Guo, W. He, A. M. Boer et al., "Elevated plasma chitotriosidase activity in various lysosomal storage disorders," Journal of Inherited Metabolic Disease, vol. 18, no. 6, pp. 717-722, 1995.

[16] R. Barone, J. Simporé, L. Malaguarnera, S. Pignatelli, and S. Musumeci, "Plasma chitotriosidase activity in acute Plasmodium falciparum malaria," Clinica Chimica Acta, vol. 331, no. 1-2, pp. 79-85, 2003.

[17] R. Barone, F. Di Gregorio, M. A. Romeo, G. Schilirò, and L. Pavone, "Plasma chitotriosidase activity in patients with $\beta$ thalassemia," Blood Cells, Molecules, and Diseases, vol. 25, no. 1, pp. 1-8, 1999.

[18] C. Borgna-Pignatti and M. R. Gamberini, "Complications of thalassemia major and their treatment," Expert Review of Hematology, vol. 4, no. 3, pp. 353-366, 2011.

[19] L. Ragab, S. Helal, N. Zaghloul et al., "Clinicovirologic analysis of hepatitis $\mathrm{C}$ infection in transfusion-dependent $\beta$-thalassemia major children," International Journal of Laboratory Hematology, vol. 32, no. 2, pp. 184-190, 2010.

[20] P. Cianciulli, "Treatment of iron overload in thalassemia," Pediatric Endocrinology Reviews, vol. 6, supplement 1, pp. 208213, 2008.

[21] R. Barone, G. Bertrand, J. Simporè, M. Malaguarnera, and S. Musumeci, "Plasma chitotriosidase activity in $\beta$-thalassemia major: a comparative study between Sicilian and Sardinian patients," Clinica Chimica Acta, vol. 306, no. 1-2, pp. 91-96, 2001.

[22] T. Matsumoto and T. Tsurumoto, "Serum YKL-40 levels in rheumatoid arthritis: correlations between clinical and laboratory parameters," Clinical and Experimental Rheumatology, vol. 19, no. 6, pp. 655-660, 2001.

[23] T. Rath, M. Roderfeld, C. Gler et al., "YKL-40 and transient elastography, a powerful team to assess hepatic fibrosis," Scandinavian Journal of Gastroenterology, vol. 46, no. 11, pp. 1369-1380, 2011.

[24] K. Huang and L.-D. Wu, "YKL-40: a potential biomarker for osteoarthritis," Journal of International Medical Research, vol. 37, no. 1, pp. 18-24, 2009.

[25] R. B. Kirkpatrick, J. G. Emery, J. R. Connor, R. Dodds, P. G. Lysko, and M. Rosenberg, "Induction and expression of human cartilage glycoprotein 39 in rheumatoid inflammatory and peripheral blood monocyte-derived macrophages," Experimental Cell Research, vol. 237, no. 1, pp. 46-54, 1997.

[26] R. G. Boot, T. A. E. Van Achterberg, B. E. Van Aken et al., "Strong induction of members of the chitinase family of proteins in atherosclerosis: chitotriosidase and human cartilage gp39 expressed in lesion macrophages," Arteriosclerosis, Thrombosis, and Vascular Biology, vol. 19, no. 3, pp. 687-694, 1999.

[27] K. C. Nishikawa and A. J. T. Millis, "gp38k (CHI3L1) is a novel adhesion and migration factor for vascular cells," Experimental Cell Research, vol. 287, no. 1, pp. 79-87, 2003.

[28] N. A. Shackel, P. H. McGuinness, C. A. Abbott, M. D. Gorrell, and G. W. McCaughan, "Novel differential gene expression in human cirrhosis detected by suppression subtractive hybridization," Hepatology, vol. 38, no. 3, pp. 577-588, 2003. 
[29] S. M. Kamal, B. Turner, Q. He et al., "Progression of fibrosis in hepatitis $\mathrm{C}$ with and without schistosomiasis: correlation with serum markers of fibrosis," Hepatology, vol. 43, no. 4, pp. 771779, 2006.

[30] Y. Saitou, K. Shiraki, Y. Yamanaka et al., "Noninvasive estimation of liver fibrosis and response to interferon therapy by a serum fibrogenesis marker, YKL-40, in patients with HCVassociated liver disease," World Journal of Gastroenterology, vol. 11, no. 4, pp. 476-481, 2005.

[31] A. Tran, S. Benzaken, M.-C. Saint-Paul et al., "Chondrex (YKL40), a potential new serum fibrosis marker in patients with alcoholic liver disease," European Journal of Gastroenterology and Hepatology, vol. 12, no. 9, pp. 989-993, 2000.

[32] C. Nøjgaard, J. S. Johansen, E. Christensen, L. T. Skovgaard, P. A. Price, and U. Becker, "Serum levels of YKL-40 and PIIINP as prognostic markers in patients with alcoholic liver disease," Journal of Hepatology, vol. 39, no. 2, pp. 179-186, 2003.

[33] Y. Wang, R. S. Ripa, J. S. Johansen et al., "YKL-40 a new biomarker in patients with acute coronary syndrome or stable coronary artery disease," Scandinavian Cardiovascular Journal, vol. 42, no. 5, pp. 295-302, 2008.

[34] C. Maccarone, G. Pizzarelli, R. Barone, and S. Musumeci, "Plasma chitotriosidase activity is a marker of recovery in transplanted patients affected by $\beta$-thalassemia major," Acta Haematologica, vol. 105, no. 2, pp. 109-110, 2001. 


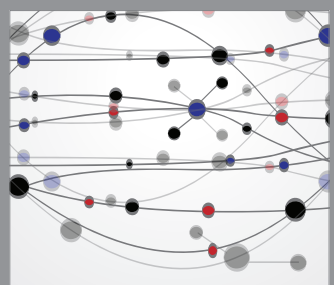

The Scientific World Journal
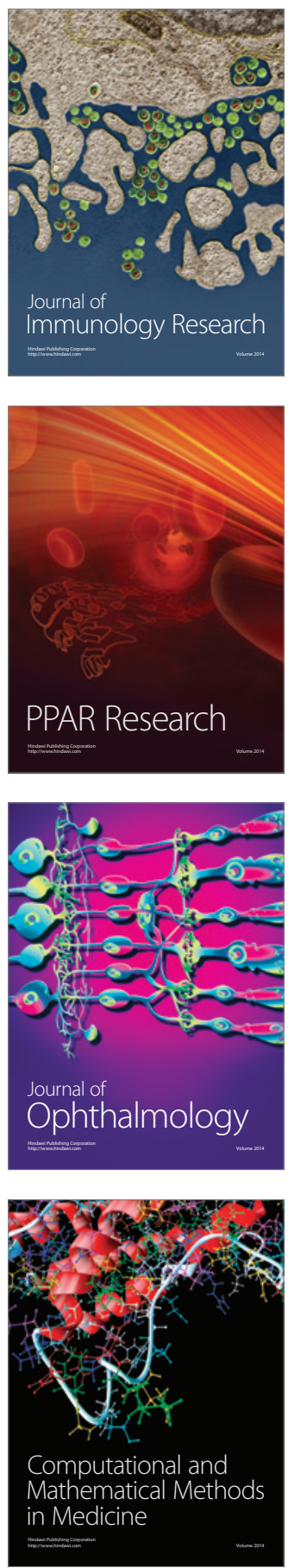

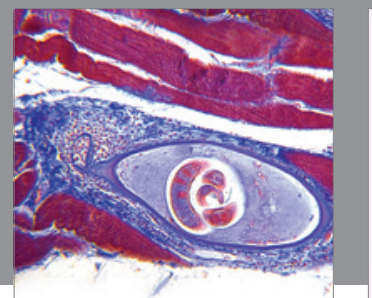

Gastroenterology

Research and Practice
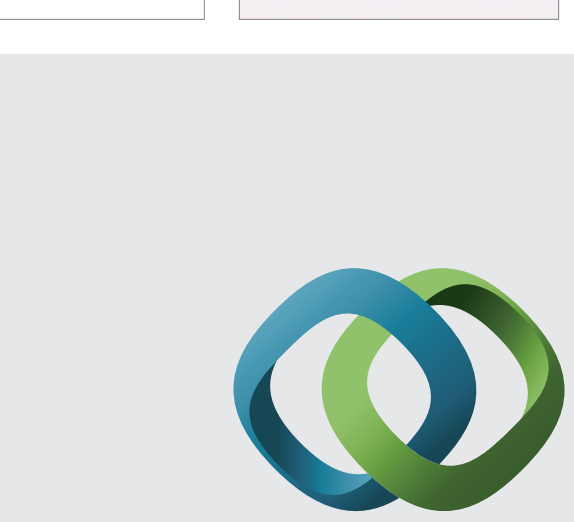

\section{Hindawi}

Submit your manuscripts at

http://www.hindawi.com
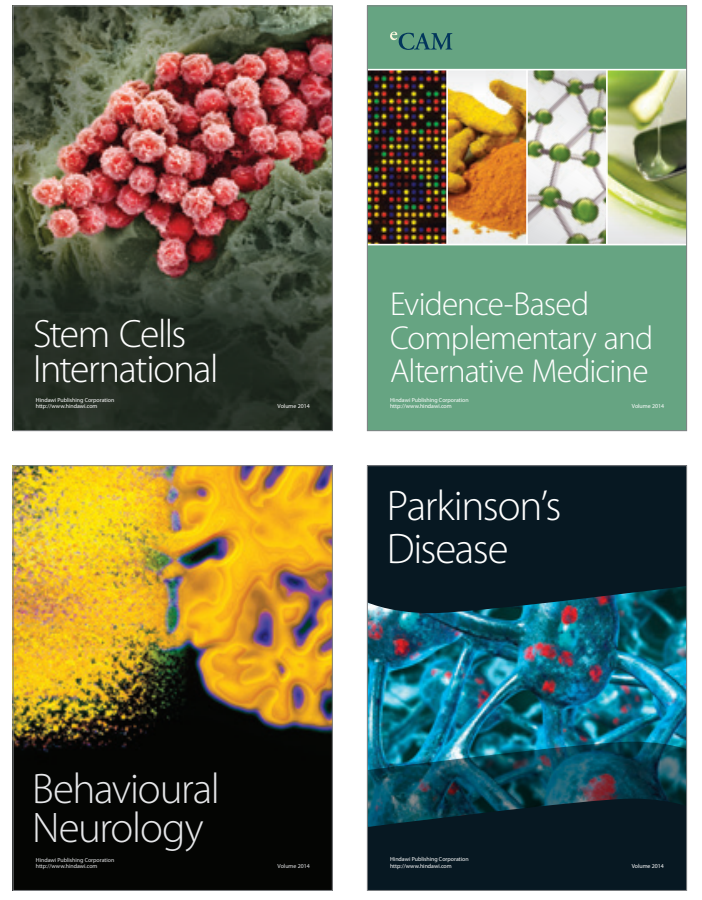
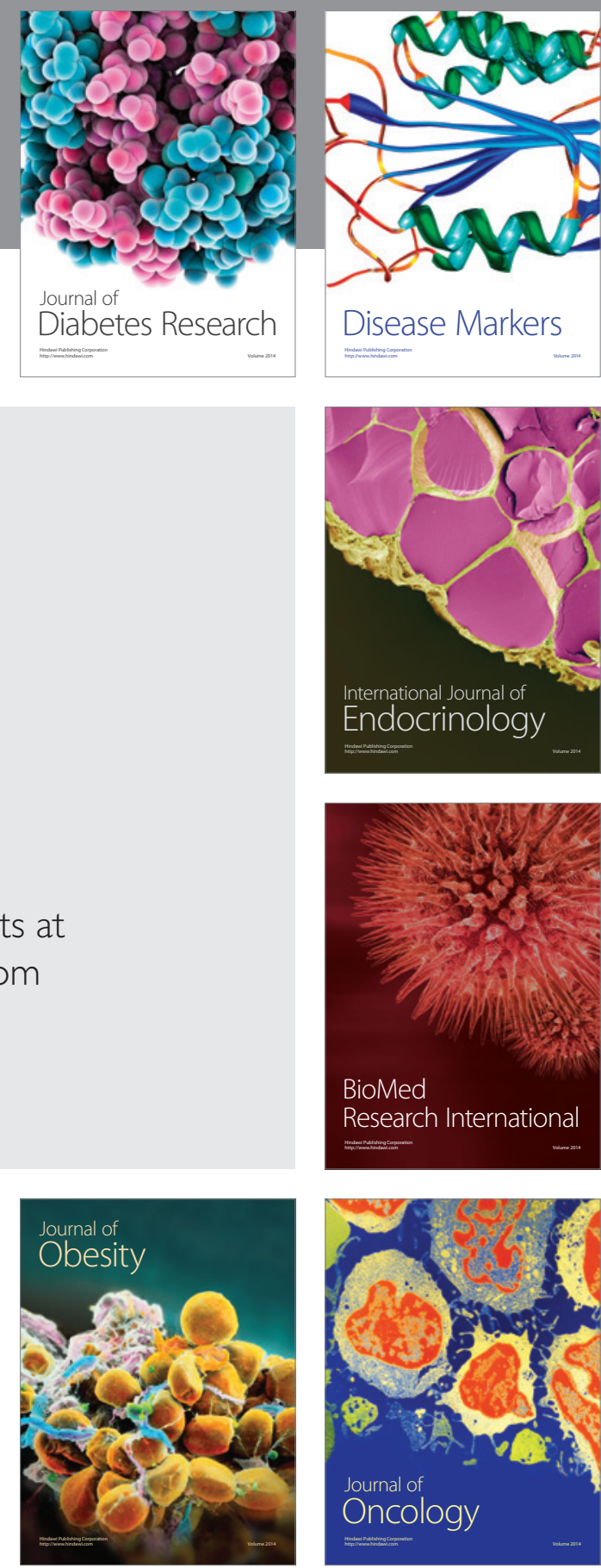

Disease Markers
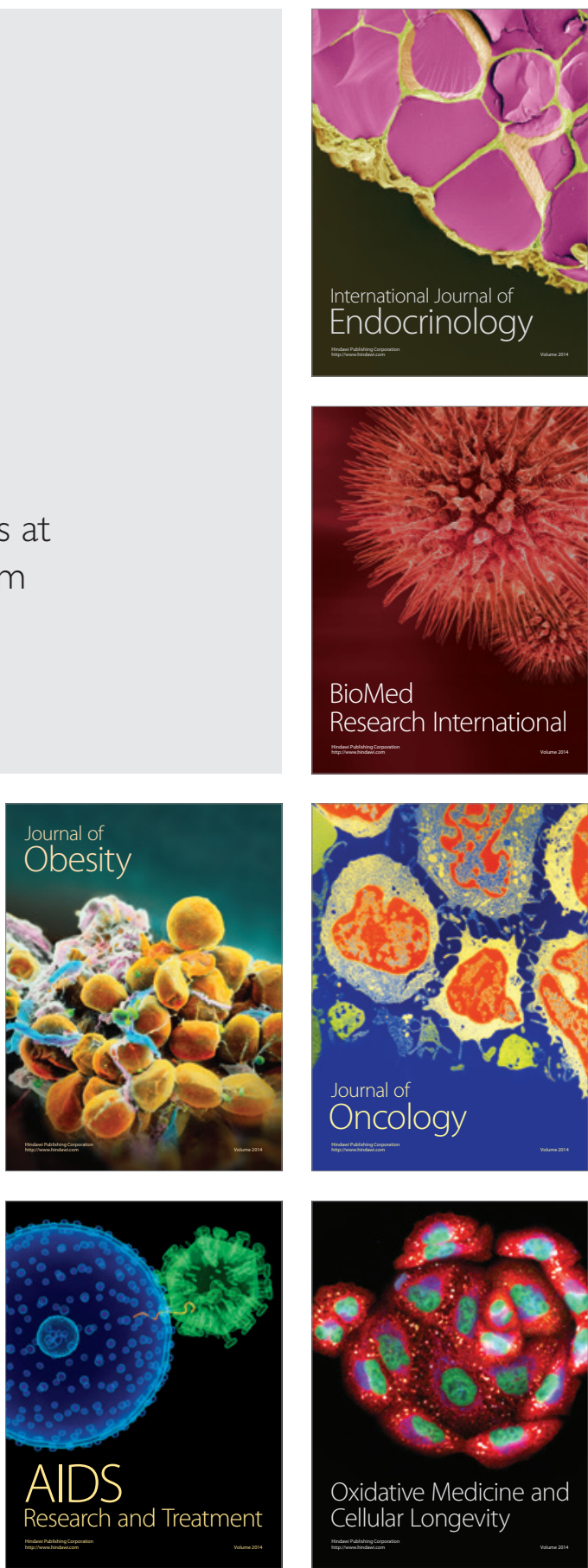